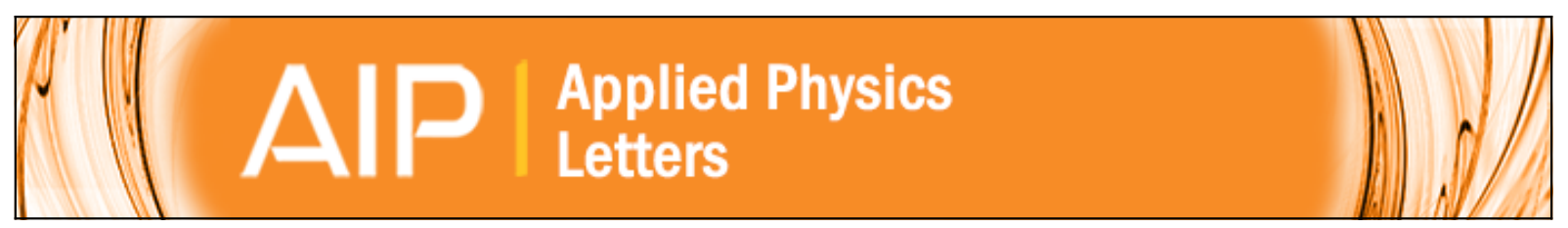

\title{
Room-temperature operation of a titanium supersaturated silicon-based infrared photodetector
}

E. García-Hemme, R. García-Hernansanz, J. Olea, D. Pastor, A. del Prado, I. Mártil, and G. González-Díaz

Citation: Applied Physics Letters 104, 211105 (2014); doi: 10.1063/1.4879851

View online: http://dx.doi.org/10.1063/1.4879851

View Table of Contents: http://scitation.aip.org/content/aip/journal/apl/104/21?ver=pdfcov

Published by the AIP Publishing

\section{Articles you may be interested in}

Capacitive infrared photodetector for room temperature operation

Appl. Phys. Lett. 102, 103108 (2013); 10.1063/1.4795520

Characteristics of a tunneling quantum-dot infrared photodetector operating at room temperature Appl. Phys. Lett. 86, 191106 (2005); 10.1063/1.1923766

Near-room-temperature operation of an InAs/GaAs quantum-dot infrared photodetector

Appl. Phys. Lett. 78, 2428 (2001); 10.1063/1.1362201

Ultrafast silicon based photodetectors

J. Vac. Sci. Technol. A 18, 630 (2000); 10.1116/1.582239

Infrared photodetection at room temperature using photocapacitance in amorphous silicon structures Appl. Phys. Lett. 72, 1229 (1998); 10.1063/1.121022

\section{AP $\mid \begin{aligned} & \text { Journal of } \\ & \text { Applied Physics }\end{aligned}$}

Journal of Applied Physics is pleased to announce André Anders as its new Editor-in-Chief 


\title{
Room-temperature operation of a titanium supersaturated silicon-based infrared photodetector
}

\author{
E. García-Hemme, ${ }^{1,2, a)}$ R. García-Hernansanz, ${ }^{1,2}$ J. Olea, ${ }^{2,3}$ D. Pastor, ${ }^{1,2,3}$ A. del Prado, ${ }^{1,2}$ \\ I. Mártil, ${ }^{1,2}$ and G. González-Díaz ${ }^{1,2}$ \\ ${ }^{1}$ Depto. de Física Aplicada III (Electricidad y Electrónica), Univ. Complutense de Madrid, 28040 Madrid, \\ Spain \\ ${ }^{2}$ CEI Campus Moncloa, UCM-UPM, 28040 Madrid, Spain \\ ${ }^{3}$ Instituto de Energía Solar, E.T.S.I. de Telecomunicación, Univ. Politécnica de Madrid, 28040 Madrid, Spain
}

(Received 5 March 2014; accepted 13 May 2014; published online 28 May 2014)

\begin{abstract}
We report room-temperature operation of $1 \times 1 \mathrm{~cm}^{2}$ infrared photoconductive photodetectors based on silicon supersaturated with titanium. We have fabricated these Si-based infrared photodetectors devices by means of ion implantation followed by a pulsed laser melting process. A high sub-band gap responsivity of $34 \mathrm{mVW}^{-1}$ has been obtained operating at the useful telecommunication applications wavelength of $1.55 \mu \mathrm{m}(0.8 \mathrm{eV})$. The sub-band gap responsivity shows a cut-off frequency as high as $1.9 \mathrm{kHz}$. These Si-based devices exhibit a non-previous reported specific detectivity of $1.7 \times 10^{4} \mathrm{~cm} \mathrm{~Hz}^{1 / 2} \mathrm{~W}^{-1}$ at $660 \mathrm{~Hz}$, under a $1.55 \mu$ m wavelength light. This work shows the potential of $\mathrm{Ti}$ supersaturated $\mathrm{Si}$ as a fully CMOS-compatible material for the infrared photodetection technology. (C) 2014 AIP Publishing LLC. [http://dx.doi.org/10.1063/1.4879851]
\end{abstract}

The field of infrared detection has always been attracting interest due to its useful variety of applications, such as military targeting and tracking, civil security and surveillance, environmental monitoring, and telecomunications. ${ }^{1,2}$ Nowadays, major infrared photo-detection technologies are based on mercury cadmium telluride, ${ }^{3,4}$ quantum-well infrared photodetectors, ${ }^{5}$ quantum-dot infrared photodetectors, ${ }^{6}$ and microbolometers. ${ }^{7}$ In spite of their high performances, these devices suffer from some important drawbacks: they are based on non-abundant or contaminant materials, their process technology is costly, they usually operate at cryogenic temperatures, and they are hardly integrated in the very mature $\mathrm{Si}$-CMOS fabrication routes. For all these reasons, a non-cooled Si-based infrared photodetector would be of a great interest since it would drastically reduce the manufacture costs enabling the integration of optical and electronic functions on a single chip.

Several groups are working in extending the infrared photoresponse of Si beyond the $1.1 \mu \mathrm{m}$ wavelength (limit defined by its optical band gap). Some groups have thoroughly investigated $\mathrm{Si}$ supersaturated with $\mathrm{S}$ or Se prepared by laser irradiation in $\mathrm{SF}_{6}$ atmosphere or by ion implantation and subsequently pulsed laser melted (PLM). ${ }^{8-12}$ An extended infrared photoresponse with high gain levels has been shown. ${ }^{13,14}$ In previous works, we have deeply investigated Si supersaturated with $\mathrm{Ti}^{15}$ or $\mathrm{V},{ }^{16}$ and we reported the first solar cell device based on Ti supersaturated $\mathrm{Si}^{17}{ }^{17}$ These materials and the solar cell device have shown a sub-band gap optical absorption coefficient in the $10^{4} \mathrm{~cm}^{-1}$ range, ${ }^{18}$ a $110 \mathrm{~K}$ photoconductive response extended up to $0.2 \mathrm{eV}$ $(6.2 \mu \mathrm{m}),{ }^{16}$ and a room-temperature sub-band gap external quantum efficiency in the $10^{-4}$ range. ${ }^{17}$ Recently, a room-temperature operated Au supersaturated Si photodiode has proven a similar sub-band gap external quantum efficiency in the $10^{-4}$ range. ${ }^{19}$

\footnotetext{
${ }^{a)}$ Electronic mail: eric.garcia@ucm.es
}

In this Letter, we present room-temperature optoelectronic properties (spectral responsivity, responsivityfrequency dependence, and spectral specific detectivity) of a photoconductive photodetector device based on Ti supersaturated Si.

High resistivity float zone (FZ) n-type Si samples $1 \times 1$ $\mathrm{cm}^{2}(\rho=200 \Omega \mathrm{cm})$, with a thickness of $300 \mu \mathrm{m}$, grown in the (111) direction, with a Hall mobility of $\mu \approx 1500$ $\mathrm{cm}^{2} \mathrm{~V}^{-1} \mathrm{~s}^{-1}$ and a carrier concentration of $\mathrm{n} \approx 2.2$ $\times 10^{13} \mathrm{~cm}^{-3}$ at room-temperature, were implanted with ${ }^{48} \mathrm{Ti}^{+}$at high doses to overcome the Mott limit. ${ }^{20}$ Similar samples were used to analyse the structural, ${ }^{21}$ electronic transport, ${ }^{22}$ and optical properties of Ti supersaturated $\mathrm{Si}^{18}$ Implantation processes were conducted in a VARIAN CF3000 Ion Implanter refurbished by Ion Beam Services with a tilt angle of $\sim 7^{\circ}$ off the incident beam axis to minimize channelling effects. Two ${ }^{48} \mathrm{Ti}^{+}$ion implantation processes were carried out to obtain a thicker layer, ${ }^{23}$ at energies of 35 and $150 \mathrm{keV}$, with doses of $10^{15}$ and $4 \times 10^{15} \mathrm{~cm}^{-2}$, respectively. The implantation parameters were designed to obtain a layer of about $200 \mathrm{~nm}$ with an almost constant $\mathrm{Ti}$ profile. After implantation, the samples were processed by PLM to recover the crystal lattice. PLM processes were performed at I. P. G. Photonics (New Hampshire, USA). PLM was conducted in air, using a $\mathrm{KrF}$ excimer laser $(248 \mathrm{~nm})$, with a $20 \mathrm{~ns}$ single pulse and an energy density of $1 \mathrm{~J} \mathrm{~cm}^{-2}$. Finally, four Ti/Al $(100 / 200 \mathrm{~nm})$ triangular contacts were e-beam evaporated in the sample corners to electrically contact and characterize the devices using the van der Pauw set up. Same metallic contacts were also evaporated over a bare Si reference sample.

The spectral responsivity characterized in this work is defined as the ratio of the electrical output signal of the detector to the wavelength dependent input radiation power, in $\mathrm{V} \mathrm{W}^{-1}$. To analyse the spectral responsivity of the $1 \times 1 \mathrm{~cm}^{2}$ devices, we fed them through two adjacent contacts with a fixed $1 \mathrm{~mA}$ current and measured the $\mathrm{AC}$ photovoltage 
generated over the opposite two contacts, while a monochromatic chopped light impinged the devices. ${ }^{15}$ A TMc300 Bentham monochromator with a Globar $(\mathrm{SiC})$ source was used as infrared monochromatic source. The intensity of the light was calibrated with a Bentham pyrometric detector. The $\mathrm{AC}$ component of the generated photovoltage was extracted out with a SR830 digital signal processing lock-in amplifier, manufactured by Stanford Research Systems (California).

Frequency dependence measurement of the responsivity was carried out using an infrared $1.55 \mu \mathrm{m}$ wavelength Thorlabs Light Emitting Diode (LED) 1550E with a wavelength long pass filter at $1.3 \mu \mathrm{m}$ illuminating the devices. The LED is powered using the output Transistor-Transistor Logic (TTL) signal of the lock-in amplifier, so we could adjust the frequency of the TTL signal in order to obtain a pulsed light and perform a frequency scan of the responsivity. Cut off frequency of the LED is $0.1 \mathrm{GHz}$, high enough to not interact with the measurements of this work. All the setups are placed in a metallic box inside-covered with black felt in order to avoid multiple reflections.

Noise spectral density $\left(S_{n}\right)$, defined as the frequency dependence of the voltage noise per unit of bandwidth root (in units of $\mathrm{V} \mathrm{Hz}^{-1 / 2}$ ), was also characterized in these devices using the SR830 lock-in amplifier. The measured responsivity and $S_{n}$ were used to calculate the specific detectivity $\left(D^{*}\right)$, which is another important photodetector characteristic, defined as ${ }^{4}$

$$
D^{*}=\frac{R \sqrt{A}}{S_{n}},
$$

where $\mathrm{R}$ is the responsivity and $\mathrm{A}$ is the optical active area of the devices. It provides information about the signal to noise ratio and is measured in units of $\mathrm{cm} \mathrm{Hz}^{1 / 2} \mathrm{~W}^{-1}$. For the spectral responsivity and $D^{*}$, the light from the source was mechanically chopped at 23 and $660 \mathrm{~Hz}$, respectively. These frequencies were chosen in order to obtain the highest responsivity and $D^{*}$ as it will be shown later.

The crystalline quality of the implanted layers was determined by cross-sectional transmission electron microscopy (XTEM) experiments at Evans Analytical Group (Sunnyvale, CA) with a JEOL 2010 TEM working at $200 \mathrm{keV}$. Simultaneously with the XTEM measurements, electron diffraction (ED) patterns with a selected area of diffraction of about $50 \mathrm{~nm}$ were obtained. We have analyzed the distribution of $\mathrm{Ti}$ in the Si layer by performing Energy Dispersive X-Ray Analysis (EDX) using the microscope in the Scanning TEM (STEM) mode and using a nominal $2 \mathrm{~nm}$ electron beam and an Oxford INCA EDX detector system.

Spectral responsivity will be the first parameter discussed in this work. Fig. 1 shows the measured spectral responsivity for the $\mathrm{Ti}$ supersaturated $\mathrm{Si}$ device, as well as for a bare Si reference device. We can observe for both devices the intrinsic photoresponse edge of the Si band gap for energies higher than $1 \mathrm{eV}$. A slight sub-band gap photoresponse is measured in the case of the $\mathrm{Si}$ reference device. There are some different possibilities to explain this minor sub-band gap response in bare Si reference devices. One of the more suitable explanations is the optical transitions involving surface states. ${ }^{24}$ Since the substrates used have a

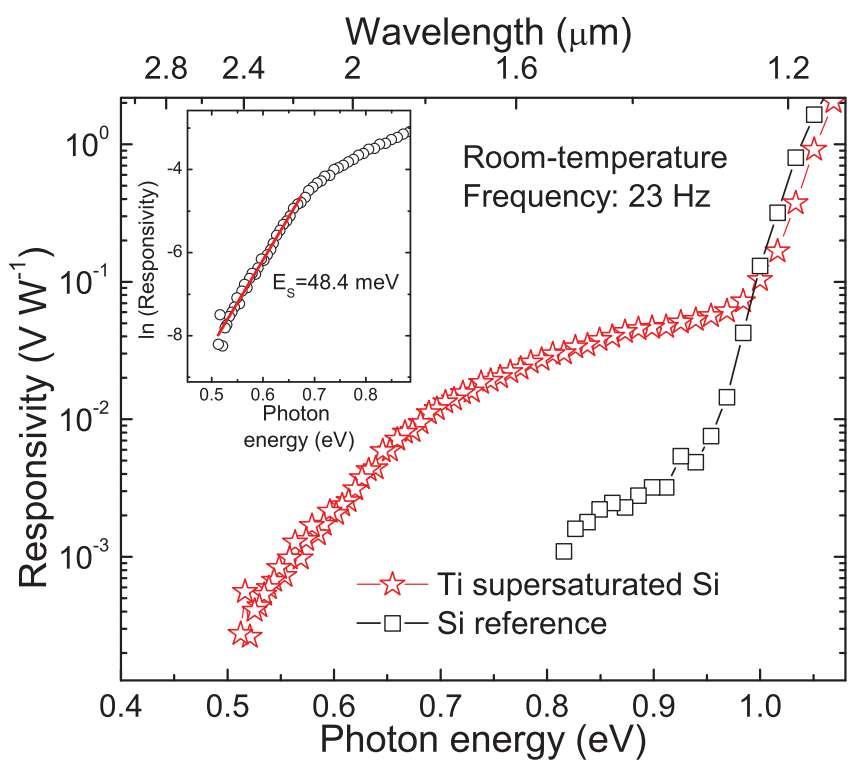

FIG. 1. Spectral room-temperature responsivity for the Ti supersaturated $\mathrm{Si}$ device and the bare silicon reference device. Inset shows the fitting to the Urbach absorption edge (Eq. (2)). Measurements performed at $23 \mathrm{~Hz}$ chopping frequency.

high purity, we can expect a high carrier lifetime. The recombination of the surface generated charge carriers will be reduced due to this high carrier lifetime. Another possibility that has been recently discussed ${ }^{19}$ to explain this subband gap photoresponse is the two photon absorption (TPA) process. ${ }^{25}$ This process is defined by the sub-band gap absorption coefficient: $\alpha_{T P A}(\lambda)=I(\lambda) \beta(\lambda)$, where $I(\lambda)$ is the radiation power density and $\beta(\lambda)$ is the TPA coefficient. $\beta(\lambda)$ values are $2-0.25 \mathrm{~cm} \mathrm{GW}^{-1}$ for $\lambda=1-2 \mu \mathrm{m}$, respectively. ${ }^{25}$ The Globar source/monochromator system used in this work has a maximum radiation density output power of $3.4 \mathrm{~mW} \mathrm{~cm}{ }^{-2}$ for $\lambda=1-2 \mu \mathrm{m}$ interval. With this radiation density power, we will obtain, in the best case, a maximum $\alpha_{T P A}(\lambda)$ of $1.5 \times 10^{-11} \mathrm{~cm}^{-1}$, which is in any case unlikely to explain the sub-band gap photoresponse of the Si reference device. In the work described in Ref. 19, the light excitation source consists in a laser diode with a much higher radiation density power. Consequently, in the present work, optical transition involving surface states seem to be the most plausible explanation. Anyway, this low sub-band gap response is measured down to $0.8 \mathrm{eV}$, where the noise floor appears at $1 \mathrm{mV} \mathrm{W}^{-1}$.

A completely different behaviour is observed in the case of the Ti supersaturated Si device. A responsivity more than one order of magnitude higher than in the Si reference device is well measured at $0.8 \mathrm{eV}(1.55 \mu \mathrm{m})$. Moreover, the responsivity extends into the infrared region of the spectrum down to $0.5 \mathrm{eV}(2.5 \mu \mathrm{m})$, reaching a much lower noise floor level of $0.26 \mathrm{mV} \mathrm{W}^{-1}$.

The sub-band gap photoresponse of the Ti supersaturated $\mathrm{Si}$ device can be further analysed for a better understanding of its nature. We can observe an exponential dependence of the responsivity beginning at $0.52 \mathrm{eV}$ with a kink in the activation tendency at about $0.72 \mathrm{eV}$. This kink energy of $0.72 \mathrm{eV}$ could be closely related to the $\mathrm{E}_{\mathrm{c}}-0.78 \mathrm{eV}$ donor deep level found in Ti doped Si devices obtained by diffusion. ${ }^{26}$ Excitation of charge carriers from the valence band (VB) to the conduction band (CB) through 
the deep level impurity could be a possible mechanism to explain the sub-band gap photoresponse. As the photon energy increases and approaches the impurity energy level, $E_{C}-E_{i}=0.78 \mathrm{eV}$, transitions from the impurity level to the conduction band become exponentially more likely. This exponential activation is the behaviour observed on the responsivity edge from 0.52 to $0.72 \mathrm{eV}$ (Fig. 1). A possible model to explain this exponential activation is based on assuming that there exists an energy broadening of the conduction band or the impurity level induced by disorders in solids. In that case, an exponential activation of the sub-band gap absorption coefficient is observed, known as the Urbach rule. ${ }^{27}$ Assuming that our spectral responsivity is proportional to the absorption coefficient, we have the dependence

$$
R\left(E_{p h}\right) \propto e^{\left(\frac{E_{p h}-E_{i}}{E_{s}}\right)},
$$

where $R\left(E_{p h}\right)$ is the spectral responsivity, $E_{i}$ is the impurity level which act as the threshold energy of the Urbach activation process $(0.72 \mathrm{eV})$, and $E_{s}$ is the slope of the Urbach absorption edge due to disorder in solids. ${ }^{27}$ Fits of the experimental data to Eq. (2) are shown in the inset of Fig. 1, and a value of $48 \mathrm{meV}$ has been extracted as the slope of the Urbach edge. This mechanism has been previously observed at low temperatures in gold-diffused $\mathrm{Si}^{28,29}$ and recently at room-temperature in gold supersaturated $\mathrm{Si}^{19}$ Moreover, the value of the slope of the Urbach edge extracted in this work ( $48 \mathrm{meV}$ ) closely matches the $42 \mathrm{meV}$ value obtained in the $\mathrm{Au}$ supersaturated $\mathrm{Si}$ devices, ${ }^{19}$ suggesting that induced energy broadening of the conduction band or the impurity level could be a common property of Si supersaturated materials with transition metals.

However, with this scenario in mind, we still have to deal with the detrimental effect that the introduction of such a high amount of $\mathrm{Ti}$ in the $\mathrm{Si}$ lattice would produce. As it is well known, $\mathrm{Ti}$ is a lifetime killer in $\mathrm{Si}^{29}$ so its presence has a harmful effect on the photogenerated charge carriers by assisting the recombination process. In the framework of the intermediate band (IB) materials, ${ }^{17,30,31}$ we could explain the increase in the responsivity in spite of the high concentration of Ti deep levels. Once the Ti concentration overcomes the Mott limit (also known as insulator-to-metal transition), ${ }^{32}$ the electron wave functions overlap producing a delocalization of the states associated to the impurities, just as it happens with the electron wave functions in the VB and in the $\mathrm{CB}$. The concentration that determines the insulator-metal transition (Mott limit) has been theoretically calculated to be approximately $6 \times 10^{19} \mathrm{~cm}^{-3}$ for a general case of study. ${ }^{20}$ This value is in agreement with experimental results in $\mathrm{Ti}$ supersaturated $\mathrm{Si}^{22}$ and $\mathrm{S}$ supersaturated $\mathrm{Si}^{33}$ Once this limit is achieved, the reduction of the recombination is possible and an increase of the charge carrier lifetime may take place, as explained in the configuration diagram theory ${ }^{20}$ and reported experimentally. ${ }^{34}$ However, we have to note that some authors, based on their theoretical calculations, do not support the predicted lifetime recovery. ${ }^{35}$ As it has been shown in Refs. 23 and 36, the Ti supersaturated Si devices investigated in this work present a Ti concentration over the theoretical limit to form an IB material, and all of the analysed properties have been well related with the predictions

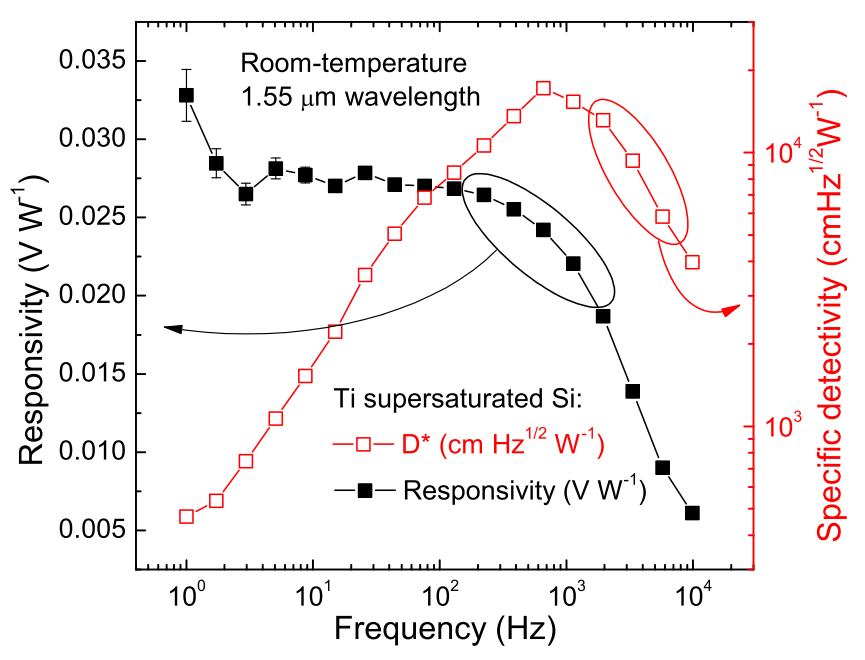

FIG. 2. Frequency dependence of the responsivity (left axis) and of the specific detectivity (right axis) for the Ti supersaturated Si device measured at room-temperature and under the $1.55 \mu \mathrm{m}$ wavelength LED light.

of the IB materials. Therefore, the sub-band gap responsivity could be a consequence of these two mechanisms: the deep levels assisted photogeneration and the reduction of the recombination process due to the formation of the IB.

Frequency-responsivity dependence is a key factor related with the response time of the devices. Fig. 2 shows the frequency dependence of the responsivity (left axis) and of the $D^{*}$ (right axis) of the $\mathrm{Ti}$ supersaturated $\mathrm{Si}$ device measured at room-temperature using the infrared $1.55 \mu \mathrm{m}$ wavelength LED setup described in the experimental. Error bars of the responsivity graph are obtained by dividing the standard deviation of the measured responsivity by the root of the number of measurements, taking into account that the responsivity is obtained as the mean value over 30 measurements. We can observe that the responsivity could be measured in a range from $1 \mathrm{~Hz}$ to $10 \mathrm{kHz}$ and presents a cut-off frequency (frequency for which the responsivity is $-3 \mathrm{~dB}$ of the nominal value) at $1.9 \mathrm{kHz}$. With such a high bandwidth, we could discard that the observed responsivity is due to thermal (bolometric) processes, ${ }^{4}$ since this kind of processes have strong frequency dependence and quite long response time, determined by the thermal mass and thermal diffusivity of the material. ${ }^{4,37}$ This observation is in contrast with the low-temperature sub-band gap photoresponse previously reported in $\mathrm{S}$ supersaturated $\mathrm{Si}$, where the sub-band gap photoresponse of the $\mathrm{S}$ supersaturated device is reported to have a strong thermal component. ${ }^{12}$

Measurement of the $S_{n}$ for the Ti supersaturated Si devices is shown and discussed in the supplementary material, ${ }^{38}$ showing a $1 / \mathrm{f}^{1 / 2}$-like noise behavior at lower frequencies and a white noise behavior at higher frequencies. Also a TEM and STEM images as well as an EDX analysis are provided in the supplementary material. ${ }^{38}$ Using the responsivity and the $S_{n}$, we are able to calculate the $D^{*}$ dependence on the frequency as it was shown in Eq. (1). Right axis of Fig. 2 shows this parameter. We can observe a high increase of the $D^{*}$ as the pulsed light frequency increases, obtaining a maximum value of $1.7 \times 10^{4} \mathrm{~cm} \mathrm{~Hz}^{1 / 2} \mathrm{~W}^{-1}$ at a frequency of $660 \mathrm{~Hz}$.

Finally, one of the most important properties of a photodetector is its spectral $D^{*}$. Fig. 3 shows the spectral $D^{*}$ measured at $660 \mathrm{~Hz}$, for the Ti supersaturated Si device and the 


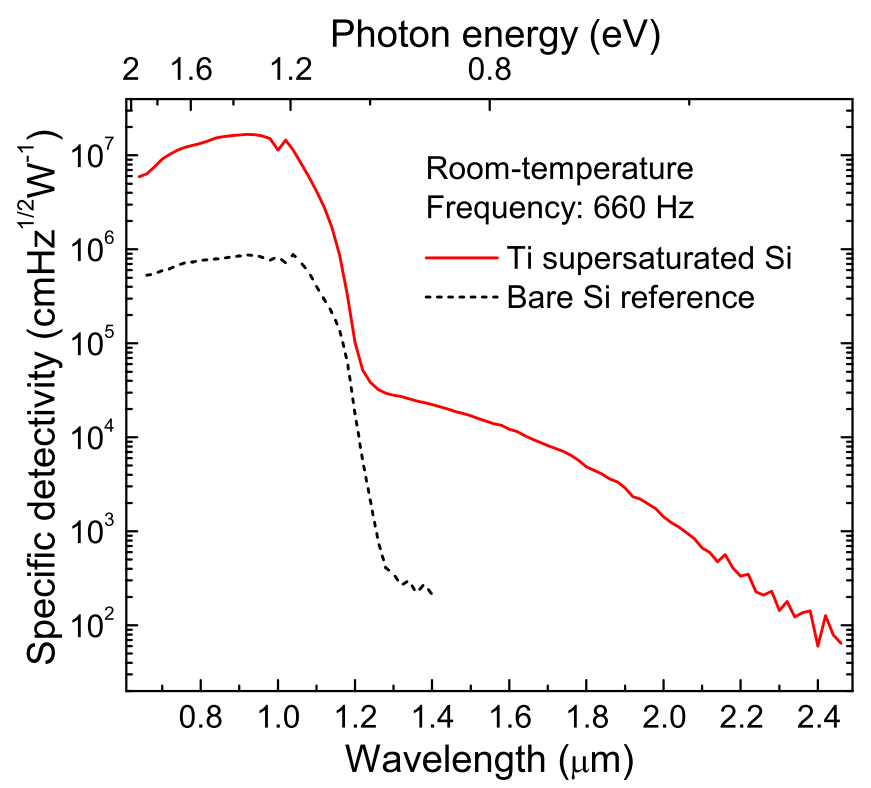

FIG. 3. Spectral room-temperature specific detectivity for the Ti supersaturated Si device and the bare Si reference device. Measurements performed at a $660 \mathrm{~Hz}$ chopping frequency.

bare $\mathrm{Si}$ reference device. We have chosen a chopping frequency of $660 \mathrm{~Hz}$ since it was the frequency at which we measured the highest $D^{*}$ (Fig. 2).

We can observe that $D^{*}$ of the bare Si reference device is almost $10^{6} \mathrm{~cm} \mathrm{~Hz}^{1 / 2} \mathrm{~W}^{-1}$ for wavelength in the range of 0.6-1.1 $\mu \mathrm{m}$ and presents an abrupt decrease for longer wavelength (sub-band gap photons energies). However, the $\mathrm{Ti}$ supersaturated $\mathrm{Si}$ device presents in the energy region above the band gap, a $D^{*}$ one order of magnitude higher than the $\mathrm{Si}$ reference device. Moreover, its $D^{*}$ is far extended into the infrared region of the spectrum, up to a $2.5 \mu \mathrm{m}$ wavelength, and presents a $D^{*}$ at $1.55 \mu \mathrm{m}$ (important band for telecommunications applications) of $1.7 \times 10^{4} \mathrm{~cm} \mathrm{~Hz}^{1 / 2} \mathrm{~W}^{-1}$. The sub-band gap increase of $D^{*}$ for the Ti supersaturated Si device is mostly due to the increase in the responsivity, as we have observed in Fig. 1. The observed increase for above-band gap photon energies is mostly due to a reduction in $S_{n}$ observed for the $\mathrm{Ti}$ supersaturated $\mathrm{Si}$ device, which presents a $1.4 \times 10^{-6} \mathrm{~V} \mathrm{~Hz}^{-1 / 2} S_{n}$ in contrast with the $1.6 \times 10^{-5} \mathrm{~V} \mathrm{~Hz}^{-1 / 2} S_{n}$ observed for the bare Si reference device. We propose that this reduction of the $S_{n}$ is mostly due to the formation of an ohmic contact between the $\mathrm{Ti}$ supersaturated $\mathrm{Si}$ device and the Ti/Al evaporated contact metals. As it was shown in Refs. 22 and 39, once the Ti concentration overcomes the Mott limit and an IB material is formed, excellent ohmic contacts are obtained. This also indicates the metallic behaviour of the IB in the Ti implanted Si layers.

Regarding the value of $D^{*}$ attained in this work, we must take into account that this photoconductor device is in a very early stage of development, and that there is plenty of room for optimizations related with device architecture. For example, applying anti-reflection coatings, optimizing contacts geometry, optical active area, or thicker layers of the $\mathrm{Ti}$ supersaturated Si absorber could derive in a higher $D^{*}$. Also studying other transition metals could improve the photodetector parameters obtained in this work. ${ }^{16}$
In conclusion, $\mathrm{Ti}$ supersaturated $\mathrm{Si}$ photodetectors operating at room-temperature have been fabricated by means of ion implantation at high doses and PLM process. The most representative properties of photodetectors have been analysed. The Ti supersaturated Si device has shown a high and extended sub-band gap responsivity up to $0.5 \mathrm{eV}(2.5 \mu \mathrm{m})$. The properties of this high sub-band gap responsivity have been explained in the context of the Urbach rule and the IB materials. An analysis of the responsivity/frequency dependence has shown a high bandwidth with a cut off frequency at $1.9 \mathrm{kHz}$. From measurements of the $S_{n}$, we have calculated the frequency dependence of the sub-band gap $D^{*}$, showing a maximum value of $1.7 \times 10^{4} \mathrm{~cm} \mathrm{~Hz}^{1 / 2} \mathrm{~W}^{-1}$ at a frequency of $660 \mathrm{~Hz}$, under a $1.55 \mu \mathrm{m}$ wavelength light. At this frequency, we have performed measurements of the spectral $D^{*}$, showing an increase of more than one order of magnitude with respect to a bare $\mathrm{Si}$ reference device and an extended $D^{*}$ into the infrared up to $2.5 \mu \mathrm{m}$. All these characteristics have shown the potential of $\mathrm{Ti}$ supersaturated $\mathrm{Si}$ materials for a room-temperature infrared imaging or telecommunication technology based on Si.

The authors would like to acknowledge the CAI de Técnicas Físicas of the Universidad Complutense de Madrid for the ion implantations and metallic evaporations. This work was partially supported by the Project NUMANCIA II (Grant No. S-2009/ENE/1477) funded by the Comunidad de Madrid. Research by E. García-Hemme was also supported by a PICATA predoctoral fellowship of the Moncloa Campus of International Excellence (UCM-UPM). J. Olea and D. Pastor thank Professor A. Martí and Professor A. Luque for useful discussions and guidance and acknowledge financial support from the MICINN within the program Juan de la Cierva (JCI-2011-10402 and JCI-2011-11471), under which this research was undertaken.

${ }^{1}$ X. Liu, B. Kuyken, G. Roelkens, R. Baets, R. M. Osgood, Jr., and W. M. J. Green, Nat. Photonics 6, 667 (2012).

${ }^{2}$ Y. Zhang, T. Liu, B. Meng, X. Li, G. Liang, X. Hu, and Q. J. Wang, Nat. Commun. 4, 1811 (2013).

${ }^{3}$ V. S. Varavin, V. V. Vasiliev, S. A. Dvoretsky, N. N. Mikhailov, V. N. Ovsyuk, Y. G. Sidorov, A. O. Suslyakov, M. V. Yakushev, and A. L. Aseev, Opto-Electron. Rev. 11, 99 (2003).

${ }^{4}$ A. Rogalski, Prog. Quantum Electron. 27, 59 (2003).

${ }^{5}$ B. F. Levine, J. Appl. Phys. 74, R1 (1993).

${ }^{6}$ S. Chakrabarti, A. D. Stiff-Roberts, X. H. Su, P. Bhattacharya, G. Ariyawansa, and A. G. U. Perera, J. Phys. D: Appl. Phys. 38, 2135 (2005).

${ }^{7}$ R. H. Dicke, Rev. Sci. Instrum. 17, 268 (1946).

${ }^{8}$ B. K. Newman, E. Ertekin, J. T. Sullivan, M. T. Winkler, M. A. Marcus, S. C. Fakra, M.-J. Sher, E. Mazur, J. C. Grossman, and T. Buonassisi, J. Appl. Phys. 114, 133507 (2013).

${ }^{9}$ D. Recht, J. T. Sullivan, R. Reedy, T. Buonassisi, and M. J. Aziz, Appl. Phys. Lett. 100, 112112 (2012).

${ }^{10}$ C. B. Simmons, A. J. Akey, J. J. Krich, J. T. Sullivan, D. Recht, M. J. Aziz, and T. Buonassisi, J. Appl. Phys. 114, 243514 (2013).

${ }^{11}$ J. T. Sullivan, R. G. Wilks, M. T. Winkler, L. Weinhardt, D. Recht, A. J. Said, B. K. Newman, Y. Zhang, M. Blum, S. Krause, W. L. Yang, C. Heske, M. J. Aziz, M. Baer, and T. Buonassisi, Appl. Phys. Lett. 99, 142102 (2011).

${ }^{12}$ J. T. Sullivan, C. B. Simmons, J. J. Krich, A. J. Akey, D. Recht, M. J. Aziz, and T. Buonassisi, J. Appl. Phys. 114, 103701 (2013).

${ }^{13}$ A. J. Said, D. Recht, J. T. Sullivan, J. M. Warrender, T. Buonassisi, P. D. Persans, and M. J. Aziz, Appl. Phys. Lett. 99, 073503 (2011).

${ }^{14}$ C. B. Simmons, J. A. Akey, J. P. Mailoa, D. Recht, M. J. Aziz, and T. Buonassisi, Adv. Funct. Mater. 2014, 201303820. 
${ }^{15}$ E. García-Hemme, R. García-Hernansanz, J. Olea, D. Pastor, A. del Prado, I. Mártil, and G. González-Díaz, Appl. Phys. Lett. 101, 192101 (2012).

${ }^{16}$ E. García-Hemme, R. García-Hernansanz, J. Olea, D. Pastor, A. del Prado, I. Mártil, and G. González-Díaz, Appl. Phys. Lett. 103, 032101 (2013).

${ }^{17}$ S. Silvestre, A. Boronat, M. Colina, L. Castañer, J. Olea, D. Pastor, A. del Prado, I. Mártil, G. González-Díaz, A. Luque, E. Antolín, E. Hernández, Í. Ramiro, I. Artacho, E. López, and A. Martí, Jpn. J. Appl. Phys. 52, 122302 (2013).

${ }^{18}$ J. Olea, A. del Prado, D. Pastor, I. Mártil, and G. González-Díaz, J. Appl. Phys. 109, 113541 (2011).

${ }^{19}$ J. P. Mailoa, A. J. Akey, C. B. Simmons, D. Hutchinson, J. Mathews, J. T. Sullivan, D. Recht, M. T. Winkler, J. S. Williams, J. M. Warrender, P. D. Persans, M. J. Aziz, and T. Buonassisi, Nat. Commun. 5, 3011 (2014).

${ }^{20}$ A. Luque, A. Martí, E. Antolín, and C. Tablero, Physica B 382, 320 (2006).

${ }^{21}$ J. Olea, M. Toledano-Luque, D. Pastor, E. San-Andres, I. Mártil, and G. González-Díaz, J. Appl. Phys. 107, 103524 (2010).

${ }^{22}$ D. Pastor, J. Olea, A. del Prado, E. García-Hemme, R. García-Hernansanz, and G. González-Díaz, Sol. Energy Mater. Sol. Cells 104, 159 (2012).

${ }^{23}$ E. García-Hemme, R. García-Hernansanz, J. Olea, D. Pastor, A. del Prado, I. Mártil, P. Wahnon, K. Sanchez, P. Palacios, and G. González-Díaz, Int. J. Photoenergy 2013, 473196.

${ }^{24}$ C. Goletti, G. Bussetti, P. Chiaradia, and G. Chiarotti, J. Phys.: Condens. Matter 16, S4289 (2004).

${ }^{25}$ A. D. Bristow, N. Rotenberg, and H. M. van Driel, Appl. Phys. Lett. 90, 191104 (2007).
${ }^{26}$ J. R. Morante, J. E. Carceller, P. Cartujo, and J. Barbolla, Solid-State Electron. 26, 1 (1983).

${ }^{27}$ M. V. Kurik, Phys. Status Solidi A 8, 9 (1971).

${ }^{28}$ S. Braun and H. G. Grimmeis, J. Appl. Phys. 45, 2658 (1974).

${ }^{29}$ M. Okuyama, N. Matsunaga, J. W. Chen, and A. G. Milnes, J. Electron. Mater. 8, 501 (1979).

${ }^{30}$ A. Luque, A. Martí, and C. Stanley, Nat. Photonics 6, 146 (2012).

${ }^{31}$ N. López, L. A. Reichertz, K. M. Yu, K. Campman, and W. Walukiewicz, Phys. Rev. Lett. 106, 028701 (2011).

${ }^{32}$ N. F. Mott, Adv. Phys. 21, 785 (1972).

${ }^{33}$ M. T. Winkler, D. Recht, M.-J. Sher, A. J. Said, E. Mazur, and M. J. Aziz, Phys. Rev. Lett. 106, 178701 (2011).

${ }^{34}$ E. Antolín, A. Martí, J. Olea, D. Pastor, G. González-Díaz, I. Mártil, and A. Luque, Appl. Phys. Lett. 94, 042115 (2009).

${ }^{35}$ J. J. Krich, B. I. Halperin, and A. Aspuru-Guzik, J. Appl. Phys. 112, 013707 (2012).

${ }^{36}$ J. Olea, D. Pastor, A. del Prado, E. García-Hemme, R. García-Hernansanz, I. Mártil, and G. González-Díaz, J. Appl. Phys. 114, 053110 (2013).

${ }^{37}$ E. Monticone, L. Boarino, G. Lerondel, R. Steni, G. Amato, and V. Lacquaniti, Appl. Surf. Sci. 142, 267 (1999).

${ }^{38}$ See supplementary material at http://dx.doi.org/10.1063/1.4879851 for the figure of the spectral noise density as a function of the frequency as well as for a TEM and STEM images and an EDX analysis of the Ti supersaturated Si material. Also some discussion is provided.

${ }^{39}$ D. Pastor, J. Olea, A. del Prado, E. García-Hemme, R. García-Hernansanz, I. Mártil, and G. González-Díaz, J. Phys. D: Appl. Phys. 46, 135108 (2013). 